\title{
Novelty and partibility as determinants of hoarding in the albino rat
}

\author{
RICHARD J. WALLACE \\ University of Oregon, Eugene, Oregon 97403
}

\begin{abstract}
Experiments on object preferences indicate that there are at least two characteristics that induce albino rats to hoard inedible objects: partible objects are hoarded in preference to nonpartible objects, and novelty results in hoarding when other object-characteristics are controlled. In addition, novel objects may be hoarded by food-deprived rats in preference to food pellets. Hoarding can therefore be integrated into a number of other motivational systems. It is suggested that an incentive concept is necessary to explain hoarding preferences in this species.
\end{abstract}

In experimental studies, hoarding by rodents has usually been described as a food storing activity (Herberg \& Blundell, 1970; Marx, 1950b; Morgan, 1947; Morgan, Stellar, \& Johnson, 1943). Field biologists have also tended to assume that this activity is specifically related to food and feeding (see Bourliére, 1956; Ewer, 1968; Hamilton, 1939). This is undoubtedly because food objects are those most commonly found in caches in the field (see lastmentioned authors), and because it suggests an obvious explanation of adaptive value in terms of survival during periods of dearth, as in the winter season (Ewer, 1968; Hamilton, 1939).

Reports based on field and on laboratory observations indicate that various rodent species retrieve objects that are inedible. Wood rats (Neotoma), for example, retrieve an assortment of inedible objects, sometimes in preference to food (see Caras, 1967; Sumner \& Dixon, 1953). Studies of wild Rattus norvegicus have indicated that this species also hoards nonfood objects. Steiniger (1950) reported that these animais would retrieve pieces of wood or mortar, and Calhoun (1962) found that pine bough tips were mixed with cached food on a few occasions (p. 100) and that wooden trap triggers were sometimes carried into the animals' harborage boxes (p. 56). In field observations of wild Norway rats, Barnett (1975) found that "stones, cakes of soap, bits of wood and much else may be accumulated", in their burrows (p. 58). Similar observations have been made of domestic strains of Norway rats when

Part of the support for writing this manuscript was provided by a research fellowship award from the National Institute of Mental Health (No. 1 F32 MH05600-01). I am grateful to Dr. D. P. Kimble and Professor S. A. Barnett for comments on earlier drafts, to Mr. 1. Fox for help with preparation of the figure, and to Ms. R. Bootes and Ms. W. Lees for typing more versions of this paper than they should have. Reprint requests should be sent to Richard J. Wallace, Department of Zoology, The Australian National University, P.O. Box 4, Canberra, ACT 2600, Australia. they were allowed to transport objects from simple enclosed areas to their home cages. Objects that these animals have retrieved in this situation include paper strips (McCain, Garrett, Reed, Mead, \& Kuenstler, 1964), food pellets wrapped in aluminum foil as opposed to unwrapped pellets (Licklider \& Licklider, 1950; Guerra \& Matheson, Note 1), and wood blocks (Tigner \& Wallace, 1972; Wallace, 1974; see also Lowney, 1958; Marx, 1950a). In each of these latter studies, retrieval of objects was frequent when food and water were available in the home cage, but declined markedly after deprivation. Similar findings have been reported when object retrieval was induced by intracranial stimulation (Mendelson, 1972; Mendelson \& Maul, 1973, 1974; Phillips, Cox, Kakolewski, \& Valenstein, 1969). In addition, carriage of inedible objects to the home cage has been observed in two other species: albino mice (Mus musculus, C3H strain) hoarded cotton dental rolls and wood blocks (Smith \& Ross, 1953), and golden hamsters (Mesocricetus auratus) hoarded glass marbies (Hammer, 1972).

In a few laboratory studies, domestic Norway rats failed to hoard wood blocks when these were presented outside their cages. This may have occurred because the animals were deprived of food (Miller \& Viek, 1944; Morgan, 1947) or because gnawing had been satiated through prior exposure to the objects (Ross, Smith, \& Nienstedt, 1950; cf. Wallace, 1974).

The observations summarized above pose problems for a conception of hoarding as a food storage mechanism. In some cases, retrieval of inedible objects may have been related to feeding; i.e., the animals retrieved objects that had features normally associated with food or that were potential food, such as novel items. This was possible even when an inedible object was chosen instead of the animal's normal food, as with the exchange of an edible for an inedible object shown by the wood rat, or the 
preference of domestic Norway rats for pellets wrapped in aluminum foil. But these hypotheses have difficulty in explaining persistent hoarding of this sort (Licklider \& Licklider, 1950). They also fail to account for the decline in hoarding of inedible objects that occurs if the animals are placed on a stringent deprivation schedule even when edible objects are not present (McCain et al., 1964; Wallace, 1974). Furthermore, it has been shown that albino rats ingest little or none of the wood blocks that they hoard, even when they are deprived of food (Wallace, 1974). Calhoun (1962) also noted that there was never any evidence of ingestion of pine bough tips by the rats that hoarded them.

Of course, some of the above instances of retrieval may have been related to nest building, e.g., hoarding of paper strips by albino rats (McCain et al., 1964) and the retrieval of cotton dental rolls by mice (Smith \& Ross, 1953). In the remaining cases it is not clear that this is a reasonable hypothesis. This includes gnawable objects, since for some rodents gnawing is an independent behavior (Morin, 1978; Price, 1973; Roberts \& Carey, 1965).

It is evident that the factors that induce retrieval of inedible objects must be determined to understand the neurobehavioral organization of hoarding and its adaptive value. In a preliminary analysis, albino rats were presented with a variety of inedible objects outside their cages. All objects were hoarded in the early trials, but consistent preferences developed as trials continued (Wallace, 1974, 1978). The objects that the rats continued to hoard shared at least one characteristic that differentiated them from the other objects, in that they could be taken apart by gnawing or tearing. In addition, almost all animals retrieved a novel nonpartible object when it was placed with the other objects at the end of the experiment. It is possible, therefore, that object novelty was responsible for retrieval during the early trials, while in later trials hoarding was related to object partibility. The present experiments were designed to test these hypotheses further.

\section{EXPERIMENT 1}

The first experiment was performed to test the hypothesis that partibility can affect retrieval. The objects presented were composed of generically similar materials and were odorless, tasteless, of the same shape and size, and about the same weight and color. Under these conditions, a marked preference for the partible object would indicate that this characteristic was a determinant of hoarding.

\section{Method}

Subjects. Seven male Sprague-Dawley (Holtzman) albino rats were bred from parents purchased from the Holtzman Company, Madison, Wisconsin. They were weaned at 26 or 29 days and placed in individual cages at 100 days of age. After weaning, they were maintained on Purina Laboratory Chow; food and water were always given ad lib (pellets were placed inside the cages in this and subsequent experiments). They were handled every 1 or 2 days after weaning. At about 70 days of age, each animal was given an initial opportunity to emerge from its cage into an adjoining alley. An emergence was recorded when the animal placed all four feet in the alley. Four animals emerged within $30 \mathrm{~min}$, with latencies of $1 \mathrm{~min} 50 \mathrm{sec}, 2 \mathrm{~min} 30 \mathrm{sec}, 4 \mathrm{~min} 35 \mathrm{sec}$, and $9 \mathrm{~min} 35 \mathrm{sec}$. At Trial $\mathrm{I}$ of the experiment they were 112 or 115 days old.

Apparatus. The apparatus consisted of the animal's home cage $(25 \times 20 \times 20 \mathrm{~cm})$ and a $61 \times 20 \times 20 \mathrm{~cm}$ plywood alley. The alley was open at one end, which was placed in front of the animal's cage during the trial, and at the other end was a bin, $20 \times 5 \times 4.5 \mathrm{~cm}$, divided by a partition. The alley was painted light blue (reflectance $=.9$ ) and covered on top with hardware cloth. In this and the next experiment, a separate alley was used for each animal. The average illuminance was $84 \mathrm{~lx}$ at the alley surface (range $=53$ to 107 ), $43 \mathrm{~lx}$ at a point $2.5 \mathrm{~cm}$ from the front of the cage and $5 \mathrm{~lx}$ at a point $2.5 \mathrm{~cm}$ from the back. During the experiment proper, the temperature was $22^{\circ}$ to $24^{\circ} \mathrm{C}$.

Procedure. In this and later experiments, trials were run during the last $4 \mathrm{~h}$ of the light part of a 12:12 light-dark cycle. Two to 3 days after the first emergence the three subjects that had not emerged were placed in their alleys for $5 \mathrm{~min}$ and given a second opportunity to emerge from their cages; all did so within $5 \mathrm{~min}$. All animals received at least two 15 -min familiarization trials during the next month and four such trials in the week before the experiment. No objects were present in the alleys on these trials. Then all were given six 20-min experimental trials on successive days. Subjects were observed on Trial 1, in order to record initial reactions to the objects, and on the last trial, to record choices after familiarization with the situation.

The objects were small cylinders of polytetrafluoroethylene (Teflon) or polymethyl methacrylate (Plexiglas), $2.5 \mathrm{~cm}$ long and $.95 \mathrm{~cm}$ in diameter. The former were milky white, the latter a light cream color. Observations with other rats indicated that the Teflon was quite partible, while the Plexiglas was not partible. To minimize the difference in weight, a hole, $.48 \mathrm{~cm}$ in diameter, was drilled in one end of each object; this was $3 \mathrm{~mm}$ deep in the Plexiglas cylinders and $2.2 \mathrm{~cm}$ in the Teflon. In neither case was the stiffness of the object affected. The mean weight of a sample of 15 objects was $2.06 \mathrm{~g}$ for the Plexiglas and $3.05 \mathrm{~g}$ for the Teflon. In earlier studies, this difference in weight between partible and nonpartible objects was reversed (Wallace, 1974, 1978). Thirty objects of each type were placed on either side of a bin on each trial, according to a semirandom order, so that no object appeared on the same side on more than two successive trials. After the last trial, a Teflon cylinder was placed in each cage for a 30 -h period, and the gnawed parts were collected to determine whether the rats ingested a portion of these objects.

In this and the next experiment, the Wilcoxon $T$ test (Siegel, 1956) was used to evaluate differences in the number of objects hoarded. In all studies the tests were two-tailed.

\section{Results}

A preference for the Teflon cylinder was found on Trial 1 and persisted throughout the experiment. The mean number of Teflon cylinders hoarded on each trial varied between 7 and 11 , while the mean number of Plexiglas cylinders hoarded was either zero or one. The difference in the mean number of Teflon and Plexiglas cylinders hoarded by each subject on Trials 1-6 was significant $[\mathrm{T}=0(\mathrm{~N}=7), \mathrm{p}<.02]$. Three of the six animals that hoarded on Trial 1 first retrieved a Plexiglas cylinder, which suggests that 
there was no initial preference. Observations on this trial also indicated that preferential Teflon hoarding began immediately after the first Teflon cylinder had been retrieved and gnawed.

The Teflon was weighed before and after Trials 3-6. On these trials, a mean of $2.3 \mathrm{~g}$ was gnawed from the objects by each animal.

The mean number of Teflon cylinders hoarded was not large; this may be because some of these subjects were nonshy (see Bindra, 1948b; Hess, 1953). If the animals that emerged at the first opportunity are considered nonshy, then the mean number of Teflon and Plexiglas cylinders hoarded by shy subjects was 12 and 2 respectively, while for nonshy subjects it was 6 and 1 . Gnawing in the alley was also observed in two nonshy animals on Trial 1 and in all four on Trial 6, while none of the shy animals gnawed in the alley.

The mean weight of the Teflon cylinders left in the cage for $30 \mathrm{~h}$ was $3.00 \mathrm{~g}$. The mean weight of the gnawed remains was $2.97 \mathrm{~g}$, indicating that little or none of the Teflon was ingested.

\section{EXPERIMENT 2}

The second experiment tested whether novelty by itself can induce hoarding and whether this is true for partible and nonpartible objects.

\section{Method}

Subjects. Twelve male Sprague-Dawley albino rats were purchased from Horton Laboratories, Oakland, California. They were housed in pairs and maintained on food pellets produced for the Department of Animal Resources, Oregon State University. They were 110 days old on Trial 1 of Part 1 of the experiment and 223 days old on Trial 1 of Part 2. Six of the eight animals used in the experiment emerged within $30 \mathrm{~min}$ at the first opportunity with latencies ranging from $30 \mathrm{sec}$ to $5 \mathrm{~min} 20 \mathrm{sec}$.

Apparatus. The apparatus was similar to that used in Experiment 1 . The mean alley illuminance was $62 \mathrm{~lx}$ (range $=60$ to 68). The mean illuminance at the front and back of the cage was 39 and $4 \mathrm{~lx}$, respectively. Temperatures were not recorded during the first part of the experiment; during the second, they ranged between $21^{\circ}$ and $24^{\circ} \mathrm{C}$.
Procedure. Subjects were given 10 familiarization trials, 10 to $15 \mathrm{~min}$ in length, on separate days, between their first emergence and the experimental trials. On all trials, each animal was run individually, while its cagemate was placed in a separate holding cage.

At the beginning of Part 1 , two glass marbles of the same color $(1.5 \mathrm{~cm}$ diam, $5.2 \mathrm{~g})$ were placed in each of the cages of four subjects and two ceramic tiles $(2.5 \times 2.5 \times .4 \mathrm{~cm}, 6.7 \mathrm{~g})$ were placed in the cages of the other four subjects. Objects were replaced every $24 \mathrm{~h}$ for 17 successive days. Eight experimental trials, 15 min each, were given from the end of the 10th 24-h period. On each of these trials, 30 marbles and 30 tiles were placed on different sides of the bin according to a semirandom order, as in the previous experiment.

The procedure during Part 2 was similar to that of the first part, except that the objects were cubes of polystyrene excelsior (about $1 \times 1.8 \times 1 \mathrm{~cm}, .1 \mathrm{~g}$ ) and tapered rolls of aluminum foil $(4.0 \times .9 \mathrm{~cm}, .53 \mathrm{~g})$. Initially 20 objects and later 15 were placed daily in each cage; this was sufficient to ensure that not all objects were gnawed. At the beginning and end of each 24-h period, objects were weighed to estimate the amount gnawed.

\section{Results}

On the initial trials of both parts of the experiment, the animals hoarded more novel objects than familiar ones (Table 1). In Part 1, the effect was found when either object was novel, particularly on the first trial. During Part 2, the difference in hoarding was largely due to those subjects for whom the packing material was novel. Apparently there was a specific preference for this object which summed with the novelty effect. Hence, after the presumed novelty of the new object had declined, both groups of subjects showed similar preferences (see Table 1). In Part 1, the difference in hoarding was statistically significant on Trial $1[\mathrm{~T}=0$ $(\mathrm{N}=7), \mathrm{p}<.01]$ and for the mean number of objects hoarded on Trials 1-8 [T $=2(\mathrm{~N}=8), \mathrm{p}<$ $.01]$. In Part 2, the difference approached significance on Trial $1[\mathrm{~T}=6(\mathrm{~N}=7), \mathrm{p}<.10]$, while it was insignificant for the averages over the entire set of trials $(\mathrm{T}=14)$.

In Part 2 of the experiment, an appreciable amount of gnawing occurred during each 24-h period. After an initial decline in gnawing for both objects, gnawing of excelsior increased from around Trial 4.

Table 1

Mean Number of Novel and Familiar Objects Hoarded in Experiment 2

\begin{tabular}{|c|c|c|c|c|c|c|c|c|}
\hline Object & Trial 1 & Trial 2 & Trial 3 & Trial 4 & Trial 5 & Trial 6 & Trial 7 & Trial 8 \\
\hline & \multicolumn{8}{|c|}{ Part 1} \\
\hline Novel Tile & 7.8 & 6.5 & 9.8 & 2.5 & 1.0 & 2.3 & 2.0 & 1.0 \\
\hline Familiar Marble & .0 & .8 & .5 & .0 & .3 & .0 & .0 & .0 \\
\hline Novel Marble & 5.0 & 2.0 & 3.3 & 2.5 & 1.8 & 1.3 & .3 & 1.5 \\
\hline \multirow[t]{2}{*}{ Familiar Tile } & .5 & 2.8 & 2.0 & 1.8 & .0 & .0 & .3 & .0 \\
\hline & \multicolumn{8}{|c|}{ Part 2} \\
\hline Novel Excelsior & 21.5 & 23.0 & 14.0 & 15.5 & 10.5 & 13.5 & 14.3 & 14.0 \\
\hline Familiar Aluminum & 8.0 & 1.8 & 1.0 & 7.8 & 3.0 & .5 & 1.3 & 1.3 \\
\hline Novel Aluminum & 6.0 & 6.0 & 4.5 & 3.3 & 4.0 & 3.0 & 1.5 & 1.8 \\
\hline Familiar Excelsior & 5.8 & 8.8 & 4.0 & 2.5 & 7.0 & 12.8 & 14.3 & 10.5 \\
\hline
\end{tabular}


The pattern of gnawing was therefore similar to the hoarding preferences.

\section{EXPERIMENT 3}

The third experiment tested whether food hoarding could be temporarily interrupted by the introduction of an inedible object when the latter was either novel or familiar.

\section{Method}

Subjects. Nine male Sprague-Dawley (Holtzman) albino rats were purchased from the Holtzman Company. They were housed individually and maintained on a diet of Purina Laboratory Chow. They were 112, 148, or 179 days old on Trial 1 of the experiment. Six animals emerged on their first opportunity with latencies ranging from 1.5 to $13.5 \mathrm{~min}$.

Apparatus. The apparatus consisted of the animals' home cages, plywood alleys like those used in Experiment 1 , and a seven-cul Lashley Ill maze whose dimensions were $124 \times 64 \times 18 \mathrm{~cm}$, with alleys $14 \mathrm{~cm}$ wide. The maze was covered with hardware cloth. A chute made by dividing a hollow plastic dowel lengthwise was fastened to the wall of one cul. For three subjects this was the fifth cul encountered by the animal, and for six it was the fourth (see Figure 1). The illuminance in the maze was $107 \mathrm{~lx}$. During the experiment, temperatures ranged between $18^{\circ}$ and $25^{\circ} \mathrm{C}$.

Procedure. Subjects were divided into groups of three, and each group was given the entire series of trials before the next group was run. Within each group, subjects were run separately. Initial emergences and familiarization trials were given in the straight alleys. Then three 20 -min trials were given in the maze with no pellets present. The animals were then placed on a 23-h deprivation schedule (which reduced them to about $85 \%$ of their weight when fed ad lib), and trials were given after a 1-h feeding period, since earlier work had shown that this procedure eliminates most of the feeding during the trial (Morgan et al., 1943). On these trials, 80 pellets were placed in the goal compartment. Trials continued in this fashion until all subjects were hoarding; two such trials were required for the first group, four for the second, and five for the third. On each of the next five trials, four inedible objects were dropped down the chute while the rat was carrying a pellet to its cage so that the objects were encountered during this retrieval. These objects were introduced only after some pellets had been hoarded; the time of introduction varied between the $3 \mathrm{rd}$ and 15 th minute of the trial.

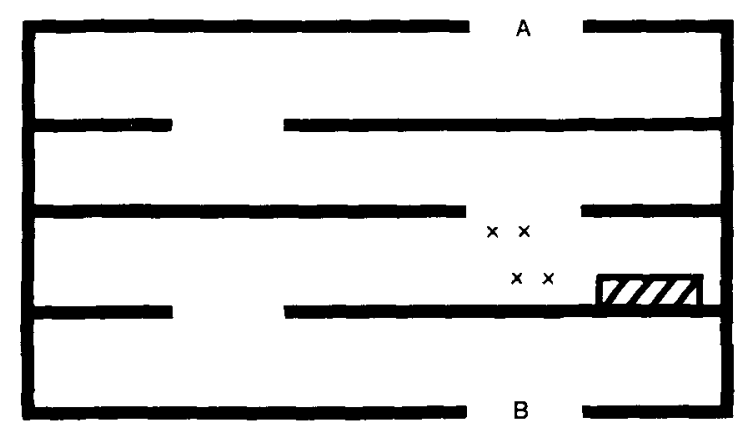

Figure 1. Plan of Lashley III maze. A and B are the entrances for three and six objects, respectively; when not used as such, the opening was blocked to form the goal compartment. Small xs indicate the approximate positions of objects introduced via the chute (cross-hatched rectangle).
Table 2

Inedible Object Hoarding When Food Pellets Were Available

\begin{tabular}{lccccc} 
& \multicolumn{5}{c}{ Trial } \\
\cline { 2 - 6 } & $1 *$ & $2 *$ & 3 & 4 & $5 *$ \\
\hline $\begin{array}{l}\text { Number of Rats "Exchanging" } \\
\text { Pellet for Inedible Object }\end{array}$ & 7 & 5 & 2 & 1 & 5 \\
$\begin{array}{l}\text { Mean Number of Inedible } \\
\text { Objects Hoarded }\end{array}$ & 2.9 & 3.1 & 1.4 & .1 & 2.1 \\
\hline
\end{tabular}

Note-Total number of rats is nine in each case. Largest possible mean is 4.0. *Inedible objects novel to subjects.

Three types of objects were used: compact balls of aluminum foil about $1.7 \mathrm{~cm}$ in diameter and weighing $.5 \mathrm{~g}$, compartments from a polyethylene ice cube tray, $1.5 \mathrm{~cm}$ on a side and weighing $.95 \mathrm{~g}$, and acorn shaped fishing lures, about $1.6 \mathrm{~cm}$ in diameter and weighing $.9 \mathrm{~g}$ (trade name Oakie Drifter, produced by the Maxwell Manufacturing Co., Vancouver, Washington, Size 3, Clown color). Each animal received one type of object on one trial, another on the next three trials, and a third on the last trial. In each group, three orders of presentation were used, so that each animal in the group received a different type of object on a given trial, and each type of object appeared as the first, second, or third equally often. Specific objects were replaced after each subject-trial.

The changes in the number of inedible objects retrieved were evaluated by computing the Wilcoxon T statistic (Siegel, 1956) for successive trials.

\section{Results}

All animals hoarded food pellets on each of the last five trials. Two to 16 were hoarded before the inedible objects were introduced; 3 to 43 were hoarded after. Table 2 shows the number of animals that retrieved an inedible object on the first encounter instead of the pellet they had been carrying, and the average number of inedible objects hoarded, for each experimental trial. Inedible objects were hoarded when they were novel (Experimental Trials 1, 2, and 5), and on these trials, the rats often left the pellet in the alley on the first encounter. The decline in hoarding with repeated presentation of the same type of object is reflected in the difference between Trials 2 and $3[T=0(N=6) p<.05]$, while the effect of introducing a novel object is reflected in the difference between Trials 4 and $5[T=2(N=9), p<$ $.01]$. No other comparisons were significant at the .05 level.

\section{GENERAL DISCUSSION}

These experiments indicate that novelty and partibility can induce hoarding in Norway rats. It also appears that these two factors can account for many of the earlier observations of inedible object retrieval. More generally, this work extends the list of object attributes that can induce hoarding in this species. Previous research has shown that sweetness (Bindra, 1948a; Wallace, 1974) and some feature of 
water (Bindra, 1947; Wallace, 1974) can also induce retrieval and determine hoarding preferences. In addition, there are presumably specific features of food objects related to retrieval (and consumption), although these have not been determined.

These results suggest that for Norway rats object retrieval can be explained by an incentive or value construct, since retrieval is always induced by a particular property of the object, whether or not there has been a change in the animal's internal state (cf. Bolles, 1975, pp. 295-296). As with rewards (see, e.g., Logan, 1960, 1965), an incentive construct may be an efficient explanation of the effects of various input variables on a particular behavior. It would also explain how an animal can choose between objects with different properties, i.e., by assuming that each object is associated with a different magnitude of incentive. In this connection, it is of particular interest that all the properties of objects that affect retrieval are also characteristics of rewards. This is well known for sweetness, "wateryness," and the presumed edibility features, as well as for contingent novelty or stimulus change (Fowler, 1965; Kish, 1966). The reinforcing effects of gnawing have also been demonstrated in a study of intracranial stimulation (Roberts $\&$ Carey, 1965). This suggests that the same construct can be used for rewards and hoarding preferences. Incidentally, this argument does not imply that an $\mathrm{r}_{\mathrm{g}}-\mathrm{s}_{\mathrm{g}}$ mechanism (see Bolles, 1975) is required. "Incentive" here refers only to a construct mediating the similar effects of various detected features on hoarding behavior. This interpretation of object retrieval is consistent with the early proposal of Bindra (1948a, 1959) that hoarding can be associated with any of a number of motivational states, and the suggestion that rodents possess a retrieval system that can function in a number of contexts (Phillips et al., 1969; Valenstein, 1973).

Another aspect of retrieval by albino rats is that the attributes associated with hoarding elicit oral behavior, e.g., feeding, drinking, and gnawing. Novelty may also have this effect, since many animals seem to engage in a kind of oral exploration of a novel object before they begin to gnaw. This is done by shifting and rotating the object while it is in the mouth and in contact with the tongue and lips. The possibility that this relation between hoarding and oral behavior reflects the organization of the neural substrate is suggested by the finding that oral responses and object retrieval are elicited by electrical stimulation in the same area of the hypothalamus (Woodworth, 1971). Also relevant in view of the relation between hoarding and rewards are demonstrations of a correspondence between reinforcing effects and differences in amount of oral behavior (Collier, 1962; Goodrich, 1960; Sheffield, Roby, \& Campbell, 1954). Together, these findings suggest that the incentive factor has concomitant effects on hoarding and oral responses as well as on oral and conditioned instrumental responses.

Experiment 3 demonstrates that the tendency to hoard a novel object can override the tendency to hoard a food pellet, even if the rat has been deprived of food. This resembles the finding that rats deprived of food or water will explore an unfamiliar environment before eating or drinking there (Chance \& Mead, 1955; Zimbardo \& Montgomery, 1957). It is therefore consistent with the view that hoarding preferences can be explained by an incentive factor. The experiment also suggests that there are inhibitory relations between "motivational systems" related to feeding and object exploration or gnawing (cf. McFarland, 1969). It was observed that the time spent mouthing or gnawing decreased markedly even on the first trial on which an object was presented. Thus an oral behavior (exploration or gnawing) and the associated retrieval tendency seemed to decline together, and then another oral behavior (feeding) and its associated retrieval tendency reemerged, as if systems of related responses were in competition.

The present results indicate that other selective pressures have influenced retrieval in this species, in addition to periods of diminished food supply. The accumulation of any object with incentive value may be adaptive, since a preference for the pertinent attribute(s) was itself selected. Retrieval may also have a safety function, because the behavior associated with the object is then performed in the burrow or other shelters [see Calhoun (1962) and Steiniger (1950) on the tendency for Rattus norvegicus to carry objects to any nearby shelter]. This is consistent with the finding that retrieval by domestic Norway rats is induced by fear of the area outside the cage (Bindra, 1948b; Hess, 1953). But, while these various pressures may have produced the patterns of retrieval shown by the Norway rat, they may not have relevance for all rodent species, particularly those that exhibit scatter as opposed to larder hoarding (Ewer, 1968; Lyall-Watson, 1963).

\section{REFERENCE NOTE}

1. Guerra, M. E., \& Matheson, D. W. Hoarding behavior: The effects of deprivation on hoarding patterns in the rat. Paper presented at the meeting of the Western Psychological Association, Los Angeles, April 1970.

\section{REFERENCES}

Barnett, S. A. The rat. A study in behavior. Chicago: Chicago University Press, 1975.

Bindra, D. Water-hoarding in rats. Journal of Comparative and Physiological Psychology, 1947, 40, 149-156.

Bindra, D. The nature of motivation for hoarding food. Journal of Comparative and Physiological Psychology, 1948, 41, 211-218.(a)

Bindra, D. What makes rats hoard? Journal of Comparative and Physiological Psychology, 1948, 41, 397-402. (b) 
BindRA, D. Motivation: A systematic reinterpretation. New York: Ronald Press, 1959.

Bolles, R. C. Theory of motivation. New York: Harper \& Row, 1975.

Bourlíre, F. [The natural history of mammals] (H. M. Parshley, trans.). New York: Knopf, 1956.

Calmoun, J. B. The ecology and sociology of the Norway rat. (Public Health Service Publication No. 1008). Washington, D.C: U.S. Government Printing Office, 1962.

Caras, R. G. North American mammals. New York: Meredith, 1967.

Chance, M. R. A., \& Mead, A. P. Competition between feeding and investigation in the rat. Behaviour, 1955, 8, 174-182.

Collier, G. Consummatory and instrumental responding as functions of deprivation. Journal of Experimental Psychology, $1962,64,410-414$.

Ewe R, R. F. Ethology of mammals. New York: Plenum, 1968.

Fowlen, H. Curiosity and exploratory behavior. New York: Macmillan, 1965.

GooDrich, K. P. Running speed and drinking rate as functions of sucrose concentration and amount of consummatory activity. Journal of Comparative and Physiological Psychology, $1960,53,245-250$.

Hamilton, W. J., JR. American mammals. New York: McGrawHill, 1939.

Hammer, L. R. Further hoarding preferences in hamsters. Psychonomic Science, 1972, 26, 139-140.

Herberg, L. J., \& Blundell, J. E. Non-interaction of ventromedial and lateral hypothalamic mechanisms in the regulation of feeding and hoarding behaviour in the rat. Quarterly Journal of Experimental Psychology, 1970, 22, 133-141.

Hess, E. H. Shyness as a factor influencing hoarding in rats. Journal of Comparative and Physiological Psychology, 1953, 46, 46-48.

KISH, G. B. Studies of sensory reinforcement. In W. K. Honig (Ed.), Operant behavior: Areas of research and application. New York: Appleton-Century-Crofts, 1966.

Licklider, L. C., \& Licklider, J. C. R. Observations on the hoarding behavior of rats. Journal of Comparative and Physiological Psychology, 1950, 43, 129-134.

LOWNEY, E. D. Characteristics of food-carrying behavior in the rat. Journal of Comparative and Physiological Psychology, $1958,51,565-569$.

Log AN, F. A. Incentive. New Haven: Yale University Press, 1960.

LogAn, F. A. Decision making by rats: Delay versus amount of reward. Journal of Comparative and Physiological Psychology, 1965, 59, 1-12.

Lyall-Watson, M. The ethology of food hoarding in mammals. Animal Behaviour, 1963, 11, 610. (Abstract)

MARx, M. H. Experimental analysis of the hoarding habit in the rat. I. Preliminary observations. Journal of Comparative and Physiological Psychology, 1950, 43, 295-308.(a)

MARX, M. H. A stimulus-response analysis of the hoarding habit in the rat. Psychological Review, 1950, 57, 80-93.(b)

McCain, G., Garkett, B. L., Reed, C., Mead, G., \& Kuenstle R, R. Effects of deprivation on hoarding of objects other than the deprived material. Animal Behaviour, 1964, 12, 409-415.

McFARLAND, D. J. Mechanisms of behavioural disinhibition. Animal Behaviour, 1969, 17, 238-242.

MENDELSon, J. Ecological modulation of brain stimulation effects. International Journal of Psychobiology, 1972, 2, 285-304.
Mendelson, J., \& Maul, G. Effects of hypothalamic current intensity on object carrying induced by shuttlebox selfstimulation in rats. Physiological Psychology, 1973, 1, 181-184.

Mendelson, J., \& Maul, G. Carrying behavior induced by shuttlebox self-stimulation in rats: Effects of food deprivation on object preference. Behavioral Biology, 1974, 10, 199-209.

Mille R, G. A., \& VieK, P. An analysis of the rat's response to unfamiliar aspects of the hoarding situation. Journal of Comparative Psychology, 1944, 37, 221-231.

Morgan, C. T. The hoarding instinct. Psychological Review, 1947, 54, 335-341.

Morgan, C. T., Stellar, E., \& Johnson, O. Food deprivation and hoarding in rats. Journal of Comparative Psychology, 1943, 35, 272-295.

Morin, L. P. Rhymicity of hamster gnawing: Ease of measurement and similarity to running activity. Physiology \& Behavior, 1978, 21, 317-320.

Phillips, A. G., Cox, V. C., Kakolewski, J., \& Valenstein, E. S. Object-carrying by rats: An approach to the behavior produced by brain stimulation. Science, 1969, 166, 903-905.

Price, E. O. Some behavioral differences between wild and domestic Norway rats: Gnawing and platform jumping. Animal Learning \& Behavior, 1973, 1, 312-316.

Roberts, W. W., \& Carey, R. J. Rewarding effect of performance of gnawing aroused by hypothalamic stimulation in the rat. Journal of Comparative and Physiological Psychology, $1965,59,317-324$.

Ross, S., Smith, W. I., \& Nienstedt, C. W., JR. The hoarding of non-relevant material by the white rat. Journal of Comparative and Physiological Psychology, 1950, 43, 217-225.

Sheffield, F. D., Roby, T. B., \& Campbell, B. A. Drive reduction versus consummatory behavior as determinants of reinforcement. Journal of Comparative and Physiological Psychology, 1954, 47, 349-354.

SIEGEL, S. Nonparametric statistics for the behavioral sciences. New York: McGraw-Hill, 1956.

Sмith, W., \& Ross, S. The hoarding behavior of the mouse. III. The storing of "non-relevant" material. Journal of Genetic Psychology, 1953, 82, 309-316.

Ste iniger, F. Beiträge zur Soziologie und sonstigen Biologie der Wanderratte. Zeitschrift für Tierpsychologie, 1950, 7, 356-379.

Sumner, L., \& Dixon, J. S. Birds and mammals of the Sierra Nevada. Berkeley: University of California Press, 1953.

Tigner, J. C., \& Wallace, R. J. Hoarding of food and nonfood items in blind, anosmic and intact albino rats. Physiology \& Behavior, 1972, 8, 943-948.

VALENSTE IN, E. S. Brain control. New York: Wiley, 1973.

Wallace, R. J. Some characteristics of hoarding behavior in the albino rat. Unpublished doctoral dissertation, University of Oregon, Eugene, 1974.

Wallace, R. J. Hoarding of inedible objects by albino rats. Behavioral Biology, 1978, 23, 409-414.

Woodworth, C. H. Attack elicited in rats by electrical stimulation of the lateral hypothalamus. Physiology \& Behavior, 1971, 6, 345-353.

Zimbardo, P. G., \& Montgomery, K. C. The relative strengths of consummatory responses in hunger, thirst, and exploratory drive. Journal of Comparative and Physiological Psychology, $1957,50,504-508$.

(Received for publication December 7, 1978; revision accepted March $19,1979$. 